Revista Brasileira de Agricultura Irrigada v.10, nº.6, p. 1023 - 1037, 2016

ISSN 1982-7679 (On-line)

Fortaleza, CE, INOVAGRI - http://www.inovagri.org.br

DOI: $10.7127 /$ rbai.v10n600482

Protocolo 482.16 - 06/09/2016 Aprovado em 13/12/2016

\title{
MAPEAMENTO DO POTENCIAL PEDOCLIMÁTICO DA CULTURA DO MILHO (Zea mays L.) PARA O ESTADO DA PARAÍBA UTILIZANDO GEOTECNOLOGIAS
}

\author{
Paulo Roberto Megna Francisco ${ }^{1}$, Djail Santos ${ }^{2}$, Eduardo Rodrigues Viana de Lima ${ }^{3}$
}

\section{RESUMO}

Este trabalho objetivou avaliar o potencial pedoclimático do Estado da Paraíba para a cultura do milho. Na obtenção dos mapas, as informações do potencial dos solos, foram cruzadas com as obtidas da aptidão climática considerando três cenários pluviométricos: anos chuvosos, regulares e secos. O cruzamento das informações foi realizado por meio de técnicas de geoprocessamento utilizando o software SPRING. Os resultados foram agrupados em cinco classes: Muito Alto, Alto, Médio, Baixo e Muito Baixo. Foram observadas diferenças significativas na extensão territorial das classes e subclasses, que apresenta variações de ordem pedológica e climática em seu território, influenciando para a cultura do milho; As áreas de potencial Muito Alto não foram mapeadas por esta metodologia; Os ambientes de potencial Baixo e Muito Baixo ocorrem em maior magnitude na região semiárida e tendem aumentar sua abrangência à medida que se acentua o grau de deficiência hídrica principalmente no cenário seco.

Palavras-chave: Geotecnologias, Planejamento de uso da terra, Potencial pedológico, Probabilidade, Aptidão climática.

\section{MAPPING OF PEDOCLIMATIC POTENTIAL OF CULTURE OF THE MAIZ (Zea mays L.) FOR THE PARAÍBA STATE USING GEOTECHNOLOGY}

\begin{abstract}
This study aimed to evaluate the potential of the soil and climate of Paraiba State for maize. In obtaining the pedoclimatic potential maps, the soil potential of information obtained were combined with the obtained climate suitability considering three rainfall scenarios: wet years, dry and regular. The crossing of the information was carried out through geoprocessing techniques using the SPRING software and obtaining maps of soil and climate potential. The result of the interpretations was classified into four pedoclimatic potential classes: Very High, High, Medium, Low and Very Low. Significant differences were observed in the territorial
\end{abstract}

\footnotetext{
${ }^{1}$ Universidade Federal da Paraíba (UFPB), Areia, PB, Brasil, paulomegna@gmail.com

${ }^{2}$ Universidade Federal da Paraíba (UFPB), Areia, PB, Brasil, santosdj@cca.ufpb.br

${ }^{3}$ Universidade Federal da Paraíba (UFPB), João Pessoa, PB, Brasil, eduvianalima@gmail.com
} 
extension of the classes and subclasses, presenting variations of pedological and climatic order in their territory, influencing the potential soil and climate for corn; The areas Very High were not mapped by this methodology; potential environments the low and very low occurring in greater magnitude in the semiarid region and tend to increase their coverage as it accentuates the water level of disability mainly in the dry scenario.

Keywords: Geotechnology, Use planning of land, Pedological potential, Probability, Climate aptitude.

\section{INTRODUÇÃO}

Em toda extensão territorial brasileira, o milho (Zea mays L.) é cultivado, destacando-se das demais culturas e ocupando assim a segunda maior área cultivada do país (CONAB, 2007). No Brasil, são produzidas, em média, 30 milhões de toneladas de grãos de milho por ano, provenientes de, aproximadamente, $57 \%$ da área nacional ocupada com cultivo de cereais. Por ser uma fonte barata de carboidratos, proteínas e óleo, com uma ampla distribuição geográfica, o milho não somente é utilizado de forma direta na dieta humana e de animais, como também tem valor industrial para produção de bebidas, medicamentos, tintas, plásticos, explosivos, etc. (LOGERCIO et al., 2002). No Nordeste do Brasil os rendimentos da cultura são muito baixos, cultivado por pequenos agricultores que utilizam pouco ou nenhum recurso tecnológico. Entretanto, apesar dos baixos rendimentos, o milho é um cereal tradicional e apresenta aspectos culturais e históricos na região (EMBRAPA, 2012).

Pela continentalidade do Brasil, observa-se que os fatores que afetam o crescimento da cultura de milho variam com a região. Nas regiões temperadas e subtropicais, a maior limitação se deve à temperatura do ar e a radiação solar (EMBRAPA, 2000). No Nordeste destacam-se a precipitação, a temperatura e a evapotranspiração da cultura. A radiação solar, a precipitação e a temperatura são os fatores de maior influência no desenvolvimento do milho, afetam as atividades fisiológicas que interferem diretamente na produção de grãos e de matéria seca (EMBRAPA, 2012).

Para a obtenção de boas produtividades a cultura do milho necessita de precipitação pluvial acima de $500 \mathrm{~mm}$ durante o ciclo; temperatura média diária acima de $19{ }^{\circ} \mathrm{C}$ e temperatura média noturna acima de $12,8{ }^{\circ} \mathrm{C}$ e abaixo de $25{ }^{\circ} \mathrm{C}$; temperaturas, no período, próximo e durante o florescimento, entre 15 a 30 ${ }^{\circ} \mathrm{C}$ e ausência de déficit hídrico (MAPA, 2014).

O milho é uma cultura de crescimento geopositivo, sua produtividade é significativamente afetada por condições de solo que limitam o aprofundamento de suas raízes sendo seu cultivo também comprometido em áreas com relevo declivoso. As maiores produtividades são obtidas em solos que apresentam textura média, bem estruturados e com boas condições de drenagem (SOUZA \& SOUZA, 2000). De acordo com EMBRAPA (2012), em relação aos aspectos pedológicos, consideram-se favoráveis ao cultivo do milho, os solos profundos, com textura variando de média a argilosa, bem drenados, destacando-se àqueles da classe dos Latossolos, Argissolos e Nitossolos.

O estudo do comportamento espacial de um determinado elemento climático, como é o caso da precipitação, é fundamental para o mapeamento de áreas de aptidão para agricultura, bem como para o planejamento das atividades agrícolas (SILVA et al., 2010). No processo de avaliação do potencial pedológico é necessário conhecer as exigências edáficas das culturas, bem como os fatores restritivos das terras. A aptidão pedológica refere-se às potencialidades e limitações intrínsecas dos solos para a produção das culturas de forma sustentável, inter-relacionando parâmetros e atributos. Na avaliação do potencial de um determinado ambiente para produção de lavouras nas condições naturais basicamente são consideradas as exigências das culturas em relação ao solo (aptidão pedológica) e em relação ao clima (aptidão climática). A partir do cruzamento dessas avaliações, chega-se a aptidão pedoclimática. Esta última, de fato, é 
que melhor representa o potencial efetivo do ambiente para a produção agrícola do ponto de vista social, econômico e ambiental (EMBRAPA, 2012).

Portanto, este trabalho objetiva associar e mapear as informações de ordem pedológica e climática, caracterizando e indicando o potencial pedoclimático do Estado da Paraíba para a cultura do milho.

\section{MATERIAL E MÉTODOS}

A área de estudo compreende o Estado da Paraíba que apresenta uma área de $56.372 \mathrm{~km}^{2}$. Seu posicionamento encontra-se entre os paralelos $6^{\circ} 02^{\prime} 12^{\prime \prime}$ e $8^{\circ} 19^{\prime} 18^{\prime \prime}$, e entre os meridianos de $34^{\circ} 45^{\prime} 54^{\prime \prime}$ e $38^{\circ} 45^{\prime} 45^{\prime \prime}$ W (FRANCISCO, 2010). O clima caracteriza-se por temperaturas médias elevadas, variando entre 22 a $30{ }^{\circ} \mathrm{C}$, uma amplitude térmica anual muito pequena, em função da baixa latitude e elevações ( $<700 \mathrm{~m})$. A precipitação varia entre $400 \mathrm{a}$ $800 \mathrm{~mm}$ anuais, nas regiões interiores semiáridas, e no Litoral, mais úmido, pode ultrapassar aos 1.600 mm (VAREJÃO-SILVA et al., 1984).

O relevo apresenta-se de forma geral bastante diversificado, constituindo-se por formas de relevo diferentes trabalhadas por diferentes processos, atuando sob climas distintos e sobre rochas pouco ou muito diferenciadas. No tocante à geomorfologia, existem dois grupos formados pelos tipos climáticos mais significativos: úmido, subúmido e semiárido. O uso atual e a cobertura vegetal caracterizam-se por formações florestais definidas como caatinga arbustiva arbórea aberta, caatinga arbustiva arbórea fechada, caatinga arbórea fechada, tabuleiro costeiro, mangues, mata-úmida, mata semidecidual, mata atlântica e restinga (PARAÍBA, 2006). As classes predominantes de solos (Figura 1) estão descritas no Zoneamento Agropecuário do Estado da Paraíba (PARAÍBA, 1978), e diferem pela diversidade geológica, pedológica e geomorfológica; atendendo também a uma diversidade de características de solo, relacionadas à morfologia, cor, textura, estrutura, declividade e pedregosidade e outras características (FRANCISCO, 2010).

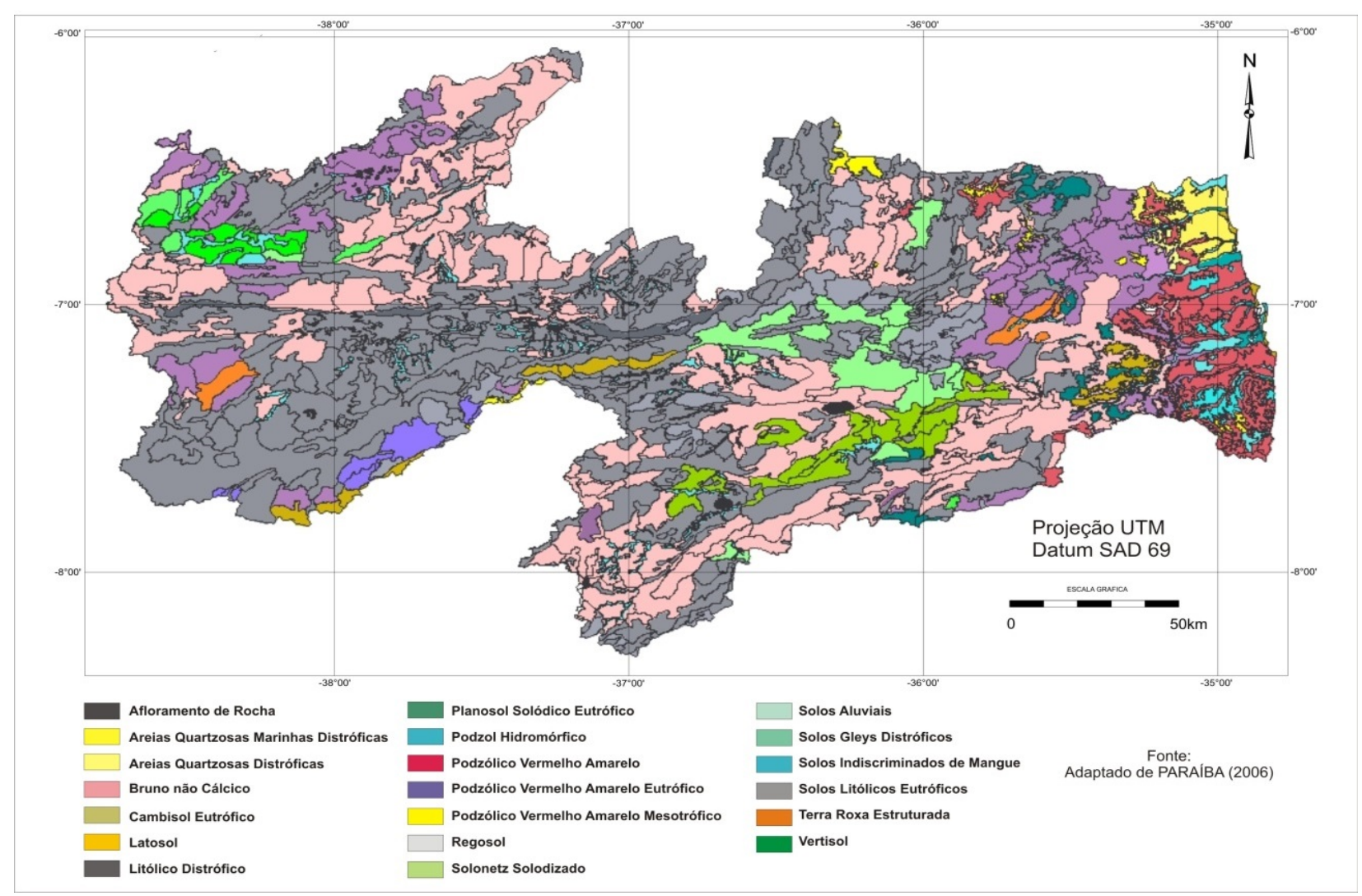

Figura 1. Solos do Estado da Paraíba. Fonte: Francisco et al. (2013). 
As classes de capacidade de uso dos solos da Paraíba estão apresentadas na fórmula básica da chave interpretativa descrita no Zoneamento Agropecuário do Estado da Paraíba (PARAÍBA, 1978), e estas se baseiam nas alternativas de uso e no grau de limitações. A caracterização das classes de capacidade de uso leva em conta principalmente a maior ou menor complexidade das práticas conservacionistas, que compreendem além das práticas de controle da erosão, as complementares, de melhoramento do solo (FRANCISCO, 2010).

Neste trabalho a base principal de dados utilizada são o Zoneamento Agropecuário do Estado da Paraíba (PARAÍBA, 1978) e o mapa de solos do Plano Estadual de Recursos Hídricos (PARAÍBA, 2006) na escala de 1:200.000, representando a área de estudo e a ocorrência e distribuição das classes de solos predominantes no Estado.

Para elaboração dos mapas foi utilizada a base de dados de Francisco et al. (2014) elaborada no software SPRING 5.2.2 na projeção UTM/SAD69, onde contém o mapa digital de solos do Plano Estadual de Recursos Hídricos (PARAÍBA, 2006) atualizado em seus limites conforme (IBGE, 2009), e o mapa de classe de capacidade de uso da terra utilizando o Zoneamento Agropecuário do Estado da Paraíba (PARAÍBA, 1978). Foi elaborada a classificação dos polígonos de solos à partir da chave da fórmula básica da classe de capacidade de uso da terra, onde foram interpretadas as unidades de solos e elaborado o mapa, sendo adotadas as cores das legendas conforme o manual de Lepsch et al. (1996).

Conforme a metodologia de PARAÍBA (1978), para a avaliação da cultura do milho foram definidas as categorias de terras que apresentam de maneira geral os grupos de terras com as seguintes aptidões:

- Categoria 1 (Aptidão Plena): áreas com classes e/ou associações de classes de capacidade de uso, que são próprias para a cultura com limitações ligeiras de utilização, impostas pelas características dos solos, topografia e erosão. Correspondem as classes de Capacidade de Uso das categorias A e B do potencial das Terras. Da categoria A: II2 a II7, III1 a III15. Da categoria B: II8, III16 e III18.
- Categoria 1a (Aptidão Plena): áreas com associações de classes de capacidade de uso com dominância de terras próprias para culturas, que apresentam limitações ligeiras de utilização, impostas pelas características dos solos, topografia e erosão. Correspondem a todas as classes de Capacidade de Uso das categorias C e C1 do potencial das Terras. Da categoria C1: II9, III19, III20, III22, III25 a III28. Da categoria C: III30, III32 a III42.

- Categoria 1b (Aptidão Plena): áreas com classes e/ou associações de classes de capacidade de uso representada por solos aluvionais, apropriados para as culturas com problemas moderados e/ou complexos de drenagem. Correspondem as classes de Capacidade de Uso das categorias E do potencial das Terras. Da categoria E: II1, III10, III21, III31 e III105.

- Categoria 2 (Aptidão Moderada): áreas com classes de capacidade de uso com limitações moderadas para utilização com a cultura, devido as características de fertilidade e/ou topografia. Correspondem as classes de Capacidade de Uso da categoria D1 do potencial das Terras. Da categoria D1: IV1 a IV5, IV9 e IV10.

- Categoria 2a (Aptidão Moderada): áreas com associações de classes de capacidade de uso da Categoria 2. Correspondem as classes de Capacidade de Uso da categoria D1 do potencial das Terras. Da categoria D1: IV6, IV7, IV11 a IV21.

- Categoria 2b (Aptidão Moderada): áreas com classes de capacidade de uso com fortes limitações para utilização com a cultura devido as características de drenagem e associações de classes de terras inaptas para a cultura. Correspondem as classes de Capacidade de Uso da categoria D2 do potencial das Terras. Da categoria D2: IV85, IV86, IV89 a IV104.

- Categoria 2c (Aptidão Moderada): áreas com classes de capacidade de uso com limitações severas para utilização com a cultura devido às características de drenagem imperfeita e associações de classes de terras inaptas para a cultura. Correspondem as classes de Capacidade de Uso da categoria F do potencial das Terras. Da categoria F: III17, III24, III29, IV22 a IV80. 
- Categoria 3 (Aptidão Restrita): áreas com classes de capacidade de uso com fortes limitações para utilização com a cultura, devido as características de baixa fertilidade do solo e/ou da drenagem excessiva. Correspondem as classes de Capacidade de Uso da categoria D2, F e G1 do potencial das Terras. Da categoria D2: IV81 a IV84. Da categoria F: IV8. Da categoria G1: VI9.

- Categoria I (Inapta): áreas impróprias para a exploração com a cultura, sendo representada por classes de capacidade de uso ou associações de classes cujas características dos solos e/ou topografia apresentam restrições severas para utilização, correspondendo as demais categorias do Potencial das Terras.

Nesta interpretação considerou-se apenas o potencial dos solos em sistema de manejo desenvolvido, que se caracteriza por aplicação mais ou menos intensiva do capital e um razoável nível de conhecimentos técnicos especializados, para a melhoria das condições dos solos e das culturas, não se justificando nem um baixo, nem um muito alto nível de manejo, com resultados duvidosos principalmente do ponto de vista econômico. As práticas de manejo são levadas a efeito, na maioria dos casos, com auxílio de tração motorizada e utilizando resultados de pesquisas agrícolas.

Para viabilizar a elaboração do mapa do potencial pedológico e também visando a padronização cartográfica os mapas foram categorizados de acordo com metodologia adaptada de EMBRAPA (2012) nas seguintes classes: Muito Alto - Categoria 1 (Aptidão Plena); Alto - Categoria 1a (Aptidão Plena); Média - Categoria 2, 2a, 2b e 2c (Aptidão Moderada); Baixo - Categoria 3 (Aptidão Restrita); Muito Baixo - Categoria I (Inapta).

Na metodologia de trabalho utilizaram-se os totais mensais de precipitações obtidos nos postos pluviométricos da Agência Executiva de Gestão das Águas do Estado da Paraíba (AESAPB). A utilização dos dados foi precedida de uma análise no tocante à sua consistência, homogeneização e no preenchimento de falhas em cada série. Para cada localidade com série de observação igual ou superior a vinte anos, foi considerado para o período disponível, independente do início.
$\mathrm{Na}$ elaboração deste trabalho foram estimadas as médias mensais de temperatura do ar naqueles locais onde apenas se dispunham de dados de chuva. Na metodologia adotada foram utilizados valores da temperatura média do ar dos últimos 30 anos estimados pelo software Estima_T (CAVALCANTI \& SILVA, 1994; CAVALCANTI et al., 2006). Na elaboração do mapa de pluviosidade foi utilizada a metodologia proposta por EMBRAPA (2012) e adaptada para o Estado da Paraíba por Francisco et al. (2015).

A discriminação dos cenários pluviométricos, anos secos, regulares e chuvosos, seguiu a metodologia proposta por EMBRAPA (2012). Para cada posto pluviométrico, foi estabelecido o total de precipitação pluviométrica registrado nos três meses consecutivos mais chuvosos de cada ano hidrológico completo. Em seguida, a distribuição gama incompleta (ASSIS et al., 1996), seguindo a conceituação de Thom (1958), foi ajustada à série desses totais em cada posto, seguindo a metodologia indicada por Mielke (1976) e utilizada pela EMBRAPA (2012). A qualidade do ajustamento da curva teórica aos valores observados foi verificada pelo teste de Kolmogorov-Smirnov (MASSEY, 1980) ao nível de significância de 95\%. Esses mesmos critérios foram aplicados em todas as séries pluviométricas. Como a curva de distribuição da chuva acumulada nos três meses consecutivos mais chuvosos é específica para cada posto, os valores correspondentes às probabilidades de 25, 50 e $75 \%$ também são específicos de cada posto (VAREJÃO-SILVA, 2001).

Os conjuntos dos anos secos, regulares e chuvosos de cada posto foram utilizados para obter as correspondentes médias mensais dos totais pluviométricos, necessárias para caracterizar os respectivos cenários. Os critérios para discriminar os anos hidrológicos de cada posto pluviométrico foram enquadrados em uma das categorias indicadas (VAREJÃO-SILVA, 2001): a) Anos secos - aqueles em que o total de precipitação, acumulado nos três meses consecutivos mais chuvosos, for igual ou menor que o valor correspondente à probabilidade de 25\%; b) Anos chuvosos - aqueles cujo total de 
precipitação, acumulado nos três meses consecutivos mais chuvosos, é superior ao valor correspondente à probabilidade de 75\%; c) Anos regulares - todos aqueles anos não classificados nas duas categorias anteriores.

Para o cálculo do balanço hídrico foram utilizados os dados obtidos para capacidade de campo de armazenamento de água no solo (CAD) de $100 \mathrm{~mm}$, onde o modelo utilizado foi o proposto por Thornthwaite (1955).

Para avaliação de aptidão climática da cultura do milho que tem o ciclo vegetativo curto, foram utilizados os critérios conforme a metodologia adaptada de EMBRAPA (2012) e utilizada por Silva et al. (2012), onde foi elaborado o evapopluviograma para cada localidade, empregados seus elementos que leva em consideração as exigências da cultura, separadamente em cada mês do seu ciclo vegetativo, expressas em termos de um ou mais dos seguintes parâmetros mensais: Pm/EPm Relação entre a precipitação e a evapotranspiração potencial no mês m; EXCm Estimativa do excedente hídrico no mês m; e DEFm - Estimativa da deficiência hídrica no mês $m$.

Os critérios utilizados para caracterizar os graus de aptidão climática do milho foram obtidos a partir do balanço hídrico climatológico mensal (VAREJÃO SILVA \& BARROS, 2002). Foram usados os índices: $\mathrm{j}=1$, 2 e 3 (cumulativo), para designar os três meses iniciais do ciclo; e i = 1, 2 ou 3 (não cumulativo) para indicar um dos três meses iniciais do ciclo; os outros dois meses foram representados por $\mathrm{k}$. Por exemplo: se $\mathrm{i}=3$, então $\mathrm{k}=1$ e 2 . O último mês (secagem e colheita) foi representado pelo índice 4. Foram adotados os parâmetros relacionados aos meses (1, 2, 3 e 4) do ciclo vegetativo (120 dias) de acordo com a Tabela 1.

Tabela 1. Critérios utilizados na avaliação de aptidão climática da cultura do milho

\begin{tabular}{ccccc}
\hline Aptidão Climática & $\begin{array}{c}\text { EXC } \\
(\mathbf{m m})\end{array}$ & DEF (mm) & P/EP (mm) & $\begin{array}{c}\text { PREC } \\
(\mathbf{m m})\end{array}$ \\
\hline $\begin{array}{c}\text { C3-Moderada por excesso } \\
\text { hídrico }\end{array}$ & $\geq 400$ & & & $\geq 700$ \\
C2-Plena com período chuvoso \\
$\begin{array}{c}\text { prolongado } \\
\text { C1-Plena sem restrição }\end{array}$ & $300<\mathrm{EXC}_{\mathrm{j}} \leq 400$ & & $\mathrm{P}_{4} / \mathrm{EP}_{4} \geq 1$ & $600<\mathrm{PREC} \leq 700$ \\
$\begin{array}{c}\text { C4-Moderada por deficiência } \\
\text { hídrica }\end{array}$ & $200<\mathrm{EXC}_{\mathrm{j}} \leq 300$ & $\mathrm{DEF}_{\mathrm{i}}<5$ & $\mathrm{P}_{4} / \mathrm{EP}_{4}<1$ & $500<\mathrm{PREC} \leq 600$ \\
$\begin{array}{c}\text { C5-Inapta por deficiência } \\
\text { hídrica acentuada }\end{array}$ & $<180<\mathrm{EXC}_{\mathrm{j}} \leq 200$ & $\mathrm{DEF}_{\mathrm{i}}<5$ & $\mathrm{P}_{4} / \mathrm{EP}_{4}<1$ & $480<\mathrm{PREC} \leq 500$ \\
& $<180$ & $\mathrm{DEF}_{\mathrm{i}} \geq 5$ & & $<480$ \\
\hline
\end{tabular}

Fonte: Adaptado de EMBRAPA (2012).

Após a obtenção dos mapas do potencial pedológico e dos mapas da aptidão climática, nos cenários pluviométricos com anos chuvosos, regulares e secos, esses dados foram cruzados utilizando-se a Linguagem Espacial Geográfica
Algébrica (LEGAL), disponível no software SPRING, e obtiveram-se os mapas do potencial pedoclimático do Estado da Paraíba para a cultura em estudo. Foram obtidas 5 classes e 25 subclasses (Tabela 2).

Tabela 2. Classes e subclasses de potencial pedoclimático

\begin{tabular}{cccccc}
\hline \multirow{2}{*}{$\begin{array}{c}\text { Potencial } \\
\text { pedológico (S) }\end{array}$} & C1 - Plena & $\begin{array}{c}\text { C2 - Plena } \\
\text { (PCP) }\end{array}$ & $\begin{array}{c}\text { C3 - } \\
\text { Moderada } \\
\text { (EH) }\end{array}$ & $\begin{array}{c}\text { C4 - Moderada } \\
\text { (DH) }\end{array}$ & C5 - Inapta \\
\hline S1 - Muito Alto & MA1 & MA2 & M3 & M4 & MB5 \\
S2 - Alto & A3 & A4 & M5 & M6 & MB6 \\
S3 - Médio & M1 & M2 & M7 & M8 & MB7 \\
S4 - Baixo & B1 & B2 & B3 & B4 & MB8 \\
S5 - Muito Baixo & MB1 & MB2 & MB3 & MB4 & MB9 \\
\hline
\end{tabular}


PCP=Período chuvoso prolongado; EH=Excesso hídrico; DH=Deficiência hídrica; MA=Muito Alta; A=Alta; M=Médio; $\mathrm{B}=$ Baixo; $\mathrm{MB}=$ Muito Baixo.

Fonte: Adaptado de EMBRAPA (2012).

Conforme a metodologia da EMBRAPA (2012), o potencial pedoclimático é restringido pela limitação de solo e/ou de clima que ocorrer com maior intensidade no ambiente. Por exemplo, ambiente com potencial pedológico Alto e com aptidão climática Inapta, terá seu potencial limitado pelo clima. Da mesma forma, as áreas com clima favorável ao cultivo, mas com potencial pedológico restritivo, terão o potencial limitado por atributos de solo.

\section{RESULTADOS E DISCUSSÃO}

Observa-se no mapa de potencial pedológico para a cultura do milho que por este trabalho não se identificou terras com potencial Muito Alto (Figura 4). Identificou-se 5.661,87 $\mathrm{km}^{2}$ de terras com Potencial Alto, representando 10,05\% (Tabela 3) da área total do Estado distribuídas na região do Litoral e do Agreste, no Curimataú e na região do Alto Sertão e do Sertão.

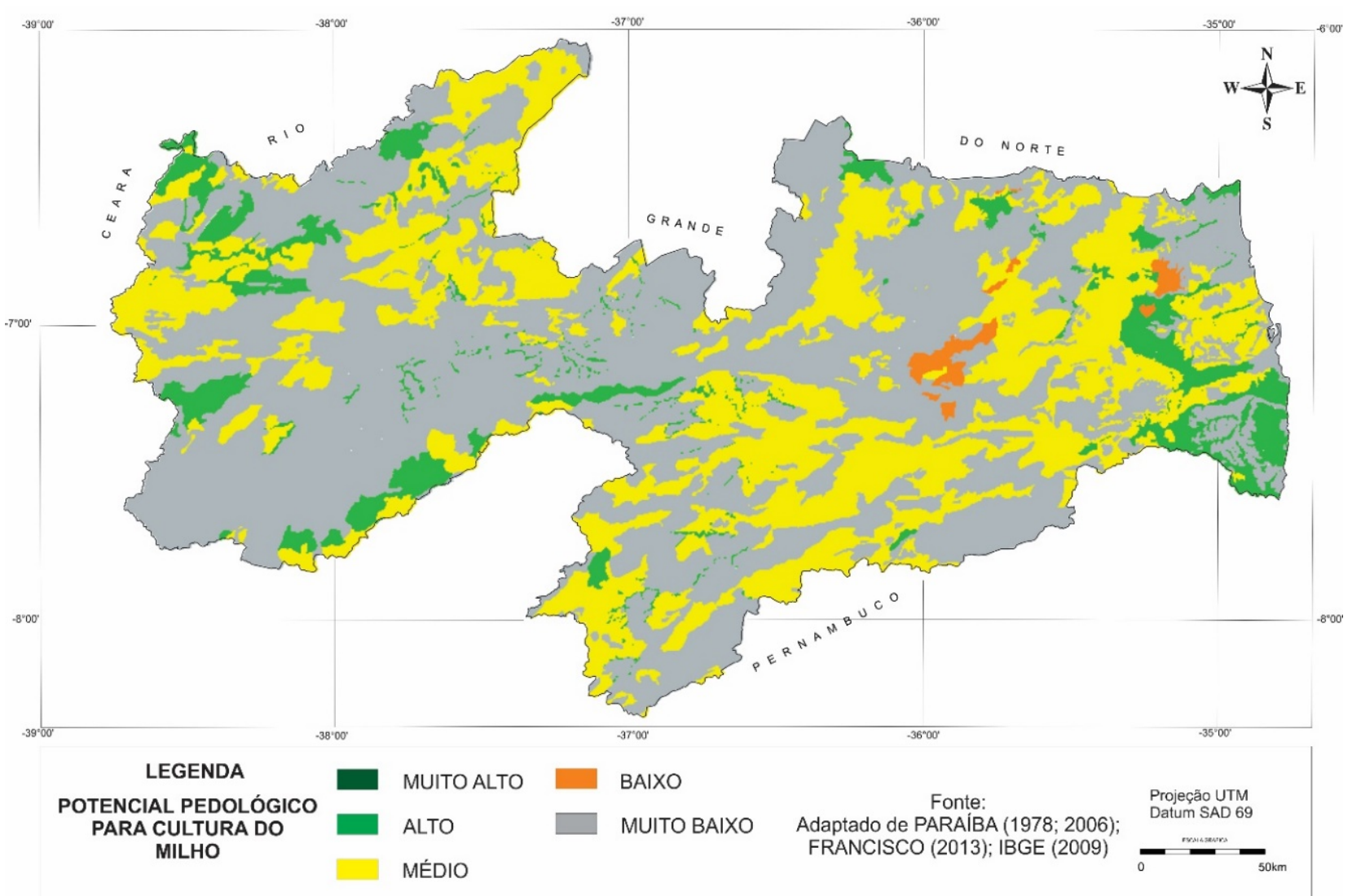

Figura 2. Potencial pedológico das terras do Estado da Paraíba para a cultura do milho.

Tabela 3. Distribuição das classes do potencial pedológico da cultura do milho

\begin{tabular}{cccccccccccc}
\hline \multicolumn{10}{c}{ Classes do Potencial Pedológico } \\
\hline Muito Alta & \multicolumn{1}{c}{ Alto } & \multicolumn{1}{c}{ Média } & \multicolumn{2}{c}{ Baixo } & Muito Baixo & \multicolumn{2}{c}{ Total } \\
\hline $\mathbf{k m}^{\mathbf{2}}$ & $\mathbf{\%}$ & $\mathbf{k m}^{\mathbf{2}}$ & $\mathbf{\%}$ & $\mathbf{k m}^{\mathbf{2}}$ & $\mathbf{\%}$ & $\mathbf{k m}^{\mathbf{2}}$ & $\mathbf{\%}$ & $\mathbf{k m}^{\mathbf{2}}$ & $\mathbf{\%}$ & $\mathbf{k m}^{\mathbf{2}}$ & $\mathbf{\%}$ \\
\hline 0,00 & 0,00 & $5.661,87$ & 10,05 & $19.448,72$ & 34,50 & 523,04 & 0,93 & $30.736,00$ & 54,52 & $56.372,00$ & 100,00 \\
\hline
\end{tabular}

Observam-se que as áreas com Potencial Médio perfazem um total de $19.448,72 \mathrm{~km}^{2}$, representando $34,5 \%$ da área total e estão distribuídas por todo o Estado. As áreas com Potencial Baixo perfazem um total de 523,04 $\mathrm{km}^{2}$, representando 0,93\% da área do Estado, 
localizadas na região ao norte do Agreste. As áreas com Potencial Muito Baixo perfazem um total de 30.736,00 $\mathrm{km}^{2}$ de terras, correspondendo a $54,52 \%$ da área total distribuídas por todo o Estado.

No mapa de aptidão climática para a cultura do milho (Figura 3), cenário seco observa-se o predomínio da classe de aptidão Inapta por deficiência hídrica acentuada (C5) em 96,55\% da área com 54.426,79 km² (Tabela 4) abrangendo quase todas as regiões do Estado.

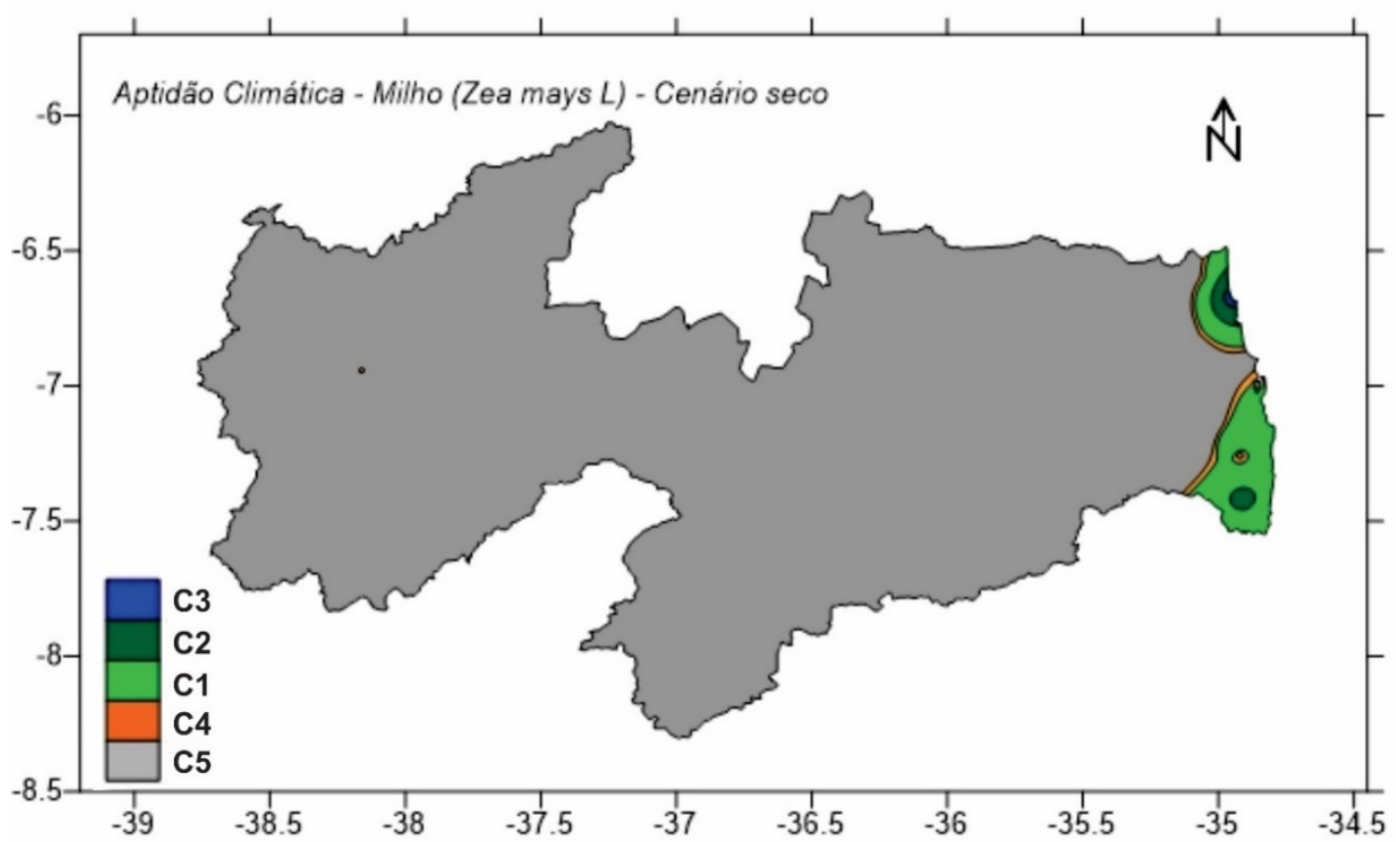

Figura 3. Aptidão climática para cultura do milho para o cenário seco.

A classe de aptidão Moderada por deficiência hídrica (C4) ocorre numa estreita faixa na região do Litoral em 255,71 $\mathrm{km}^{2}$, ocupando 0,45\% da área do Estado. Observa-se que $0,04 \%$ da área do Estado em 22,84 $\mathrm{km}^{2}$ (Tabela 4), apresenta aptidão climática Moderada por excesso hídrico (C3) localizada somente na região do Litoral norte. A classe de aptidão climática Plena com período chuvoso prolongado (C2) com 202,41 km² representando
0,36\% da área total, ocorre na região do Litoral. Observa-se que 2,6\% da área do Estado apresenta aptidão climática Plena (C1), com 1.464,25 km², ocorrendo na região do Litoral.

Para o cenário regular (Figura 4), observa-se que $11,01 \%$ da área do Estado (Tabela 4), apresenta aptidão climática Plena (C1), com 6.205,93 km², ocorrendo na região do Litoral e em pequena região do Brejo e na região do Sertão.

Tabela 4. Classes de aptidão climática para cultura do milho nos três cenários pluviométricos

\begin{tabular}{cccccccc}
\hline \multirow{2}{*}{ Legenda } & \multirow{3}{*}{ Aptidão climática } & \multicolumn{4}{c}{ Cenário pluviométrico } \\
\cline { 3 - 7 } & & $\mathbf{k m}^{\mathbf{2}}$ & $\mathbf{9}$ & $\mathbf{k m}^{\mathbf{2}}$ & $\mathbf{\%}$ & $\mathbf{k m}^{\mathbf{2}}$ & $\mathbf{\%}$ \\
\hline & Plena & $1.464,25$ & 2,60 & $6.205,93$ & 11,01 & $9.587,75$ & 17,00 \\
C2 & Plena com período chuvoso prolongado & 202,41 & 0,36 & $1.192,66$ & 2,11 & $13.460,77$ & 23,88 \\
C3 & Moderada por excesso hídrico & 22,84 & 0,04 & $1.153,79$ & 2,04 & $4.894,31$ & 8,68 \\
C4 & Moderada por deficiência hídrica & 255,71 & 0,45 & $3.435,12$ & 6,09 & $1.047,27$ & 1,86 \\
C5 & Inapta por deficiência hídrica acentuada & $54.426,79$ & 96,55 & $44.384,50$ & 78,75 & $27.381,90$ & 48,58 \\
\hline
\end{tabular}




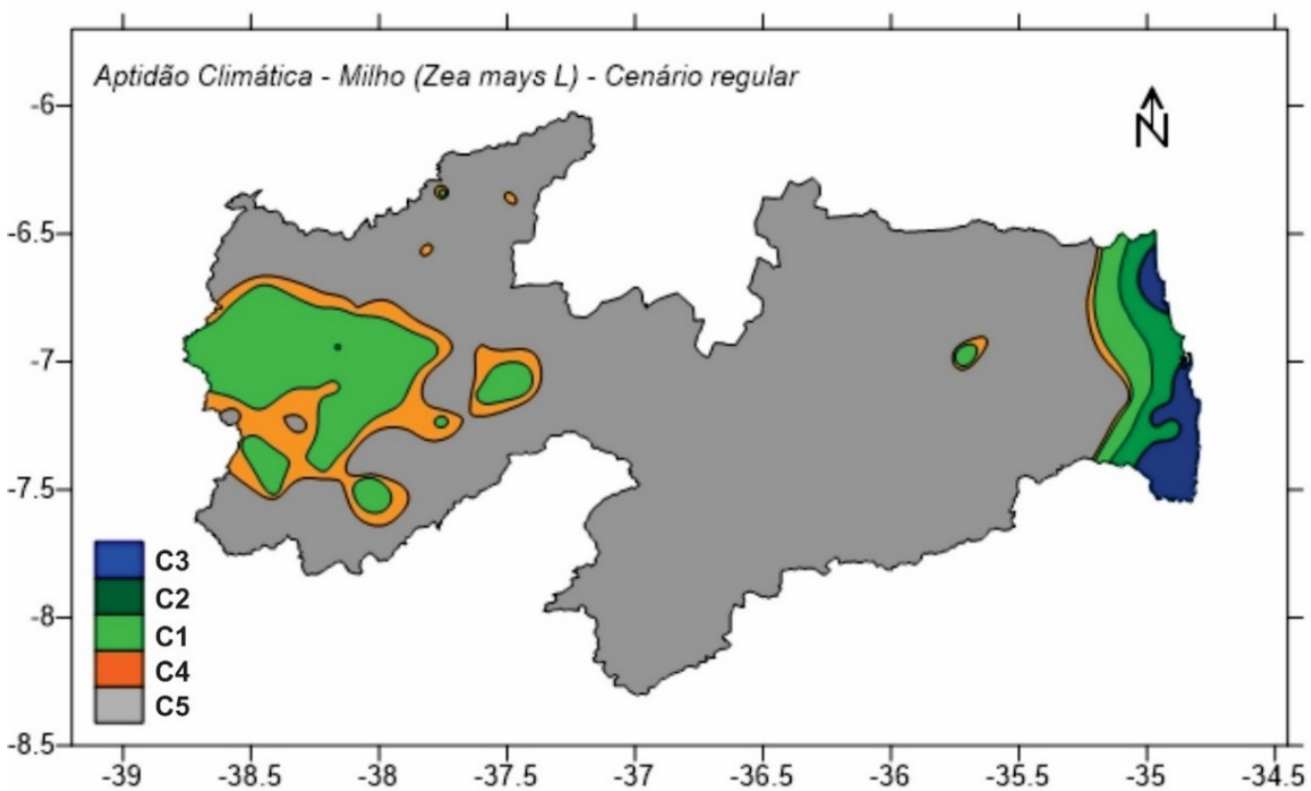

Figura 4. Aptidão climática para cultura do milho para o cenário regular.

A classe de aptidão climática plena com período chuvoso prolongado (C2) com $1.192,66 \mathrm{~km}^{2}$ representando 2,11\% da área total, ocorre somente na faixa litorânea. Observa-se que 2,04\% da área do Estado em 1.153,79 km² (Tabela 2), apresenta aptidão climática Moderada por excesso hídrico (C3) localizada na região do Litoral. Para a classe Moderada por deficiência hídrica (C4) observa-se que ocorrem em pequena faixa estreita entre as classes C5 e C1 no Litoral, Brejo e Sertão, com 3.435,12 km² representando 6,09\% da área total. A classe de aptidão Inapta por deficiência hídrica acentuada (C5), com 44.384,50 km² representando 78,75\% da área total, abrange boa parte do Agreste e Brejo, a região do Cariri/Curimataú sobre o planalto da Borborema e parte do Sertão.

No mapa de aptidão climática para a cultura do milho no cenário chuvoso (Figura 5), observa-se que $8,68 \%$ da área do Estado em 4.894,31 $\mathrm{km}^{2}$ (Tabela 4), apresenta aptidão climática Moderada por excesso hídrico (C3) localizada na região do Litoral e do Sertão.

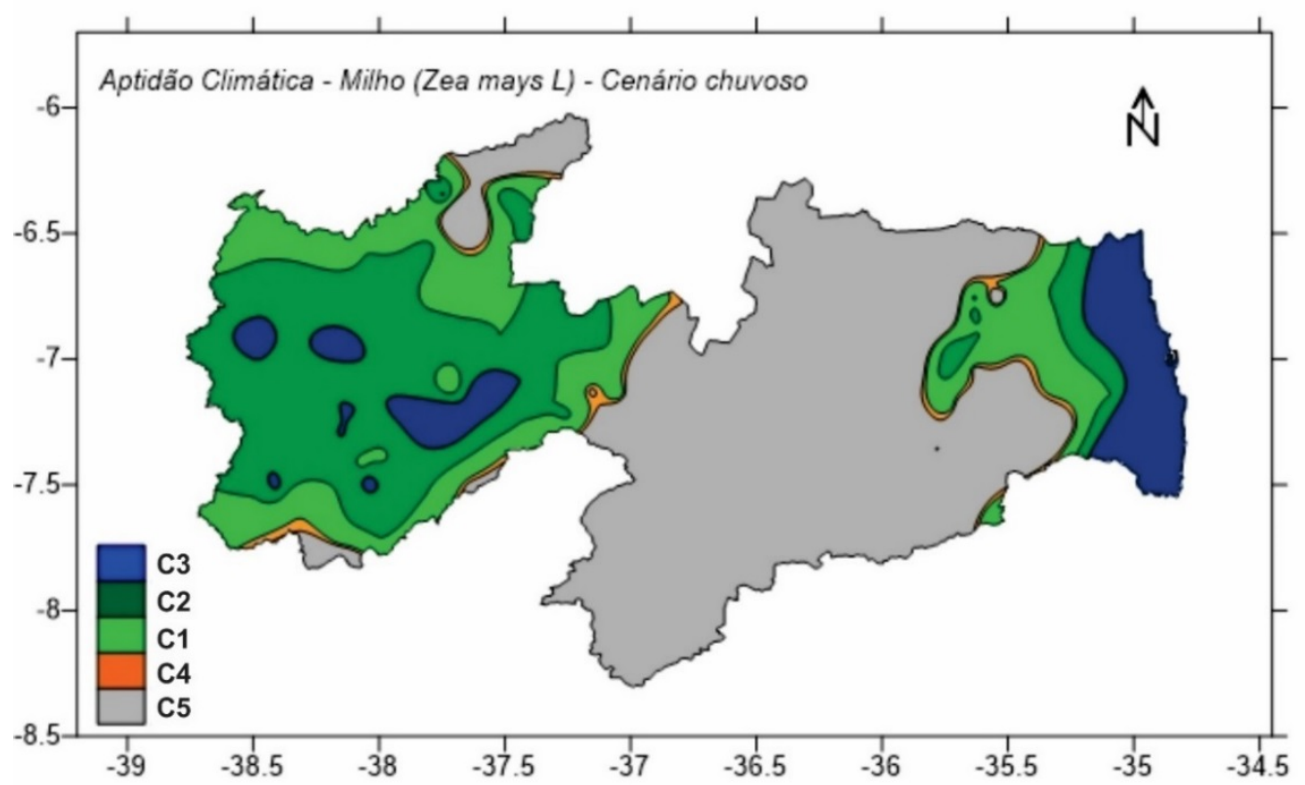

Figura 5. Aptidão climática para cultura do milho para o cenário chuvoso. 
A classe de aptidão climática Plena com período chuvoso prolongado (C2) com $13.460,77 \mathrm{~km}^{2}$ representando $23,88 \%$ da área total, ocorre na faixa Litorânea, do Agreste e Brejo, na região central do Sertão. A classe de aptidão Plena (C1), com 9.587,75 km² representando $17 \%$ da área total, ocorre nas regiões do Agreste, Brejo e em torno dos contrafortes do Sertão e Alto Sertão. A classe de aptidão climática Moderada por deficiência hídrica (C4) observa-se que ocorrem em pequenas faixas estreitas entre as classes $\mathrm{C} 1 \mathrm{e}$ C3, com 1.047,27 km² representando 1,86\% da área total. A classe de aptidão Inapta por deficiência hídrica acentuada (C5), com 27.381,90 $\mathrm{km}^{2}$ representando 48,58\% da área total, abrange todo o planalto da Borborema nas regiões do Cariri e do Curimataú, na região do Agreste e na região do Sertão em direção voltada ao Estado do Rio Grande do Norte.
No mapa de potencial pedoclimático para cultura do milho cenário seco (Figura 6) as áreas da classe Alta abrangem 718,33 $\mathrm{km}^{2}$, representando $1,27 \%$ da área total do Estado (Tabela 5), com ocorrência das subclasses A3 e A4, predominando a subclasse A3. Estas classes ocorrem na região do Litoral, notadamente em ambientes por apresentarem solos de potencial pedológico Alto, e aptidão climática plena com período chuvoso prolongado. Os ambientes de potencial Médio abrangem 295,56 km², representando 0,52\% da área total, com ocorrência das subclasses M1, M6 e M8, com predomínio da subclasse M1. Estas classes ocorrem principalmente na região do Litoral notadamente em ambientes por apresentarem solos de potencial pedológico Médio, e aptidão climática Plena e Moderada por deficiência.

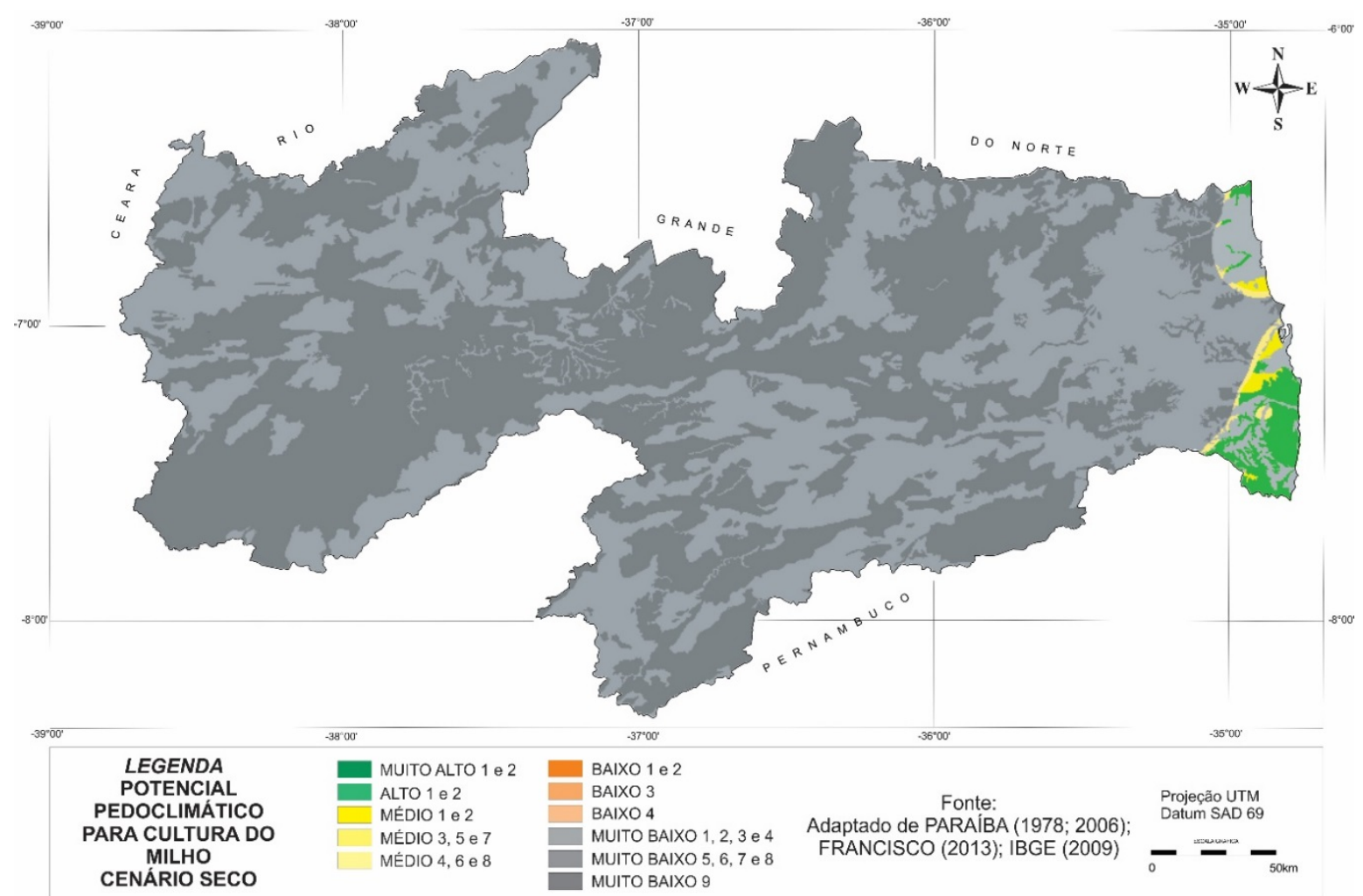

Figura 6. Potencial pedoclimático para cultura do milho cenário seco.

As áreas de potencial Baixo para o cenário seco não apresentaram mapeadas neste trabalho. Já as áreas de potencial Muito Baixo contemplam os ambientes com fortes limitações de solo e/ou de clima, abrangem 55.358,12 $\mathrm{km}^{2}$, representando $98,2 \%$ da área, com ocorrência das subclasses MB1, MB2, MB4, MB6, MB7, MB8 e MB9, predominando a subclasse MB9. Estas classes ocorrem principalmente sob o Planalto da Borborema por apresentarem aptidão climática Inapta. 
Tabela 5. Classes de aptidão pedoclimática para cultura do milho

\begin{tabular}{|c|c|c|c|c|c|c|c|}
\hline \multirow{2}{*}{ Classe } & \multirow{2}{*}{ Subclasse } & \multicolumn{6}{|c|}{ Cenário } \\
\hline & & Seco & $\%$ & Regular & $\%$ & Chuvoso & $\%$ \\
\hline \multirow{2}{*}{ Muito Alta } & MA1 & - & - & - & - & - & - \\
\hline & MA2 & - & - & - & - & - & - \\
\hline \multirow{2}{*}{ Alta } & A3 & 672,17 & 1,19 & 610,39 & 1,08 & $1.593,41$ & 2,83 \\
\hline & A4 & 46,16 & 0,08 & 292,95 & 0,52 & $1.760,69$ & 3,12 \\
\hline \multirow{8}{*}{ Média } & M1 & 141,43 & 0,25 & $2.151,66$ & 3,82 & $3.228,27$ & 5,73 \\
\hline & M2 & - & - & 371,58 & 0,66 & $3.855,79$ & 6,84 \\
\hline & M3 & - & - & - & - & - & - \\
\hline & M4 & - & - & - & - & - & - \\
\hline & M5 & - & - & 581,14 & 1,03 & $1.135,05$ & 2,01 \\
\hline & M6 & 68,71 & 0,12 & 539,24 & 0,96 & 82,65 & 0,15 \\
\hline & M7 & - & - & 41,60 & 0,07 & $1.037,51$ & 1,84 \\
\hline & M8 & 85,41 & 0,15 & 599,77 & 1,06 & 336,18 & 0,60 \\
\hline \multirow{4}{*}{ Baixa } & B1 & - & - & 49,71 & 0,09 & 36,22 & 0,06 \\
\hline & B2 & - & - & - & - & 76,88 & 0,14 \\
\hline & B3 & - & - & - & - & 46,23 & 0,08 \\
\hline & B4 & - & - & 39,56 & 0,07 & 7,13 & 0,01 \\
\hline \multirow{9}{*}{ Muito Baixa } & MB1 & 648,18 & 1,15 & $3.392,62$ & 6,02 & $4.722,43$ & 8,38 \\
\hline & MB2 & 156,15 & 0,28 & 527,64 & 0,94 & $7.764,25$ & 13,77 \\
\hline & MB3 & 22,83 & 0,04 & 528,83 & 0,94 & $2.671,96$ & 4,74 \\
\hline & MB4 & 101,36 & 0,18 & $2.255,38$ & 4,00 & 619,47 & 1,10 \\
\hline & MB5 & - & - & - & - & - & - \\
\hline & MB6 & $4.871,07$ & 8,64 & $3.634,40$ & 6,45 & $1.085,55$ & 1,93 \\
\hline & MB7 & $19.214,79$ & 34,09 & $16.273,96$ & 28,87 & $10.983,89$ & 19,48 \\
\hline & MB8 & 522,74 & 0,93 & 433,47 & 0,77 & 356,27 & 0,63 \\
\hline & MB9 & $29.821,00$ & 52,90 & $24.048,11$ & 42,66 & $14.972,17$ & 26,56 \\
\hline Total & & $56.372,00$ & 100,00 & $56.372,00$ & 100,00 & $56.372,00$ & 100,00 \\
\hline
\end{tabular}

No mapa de potencial pedoclimático para cultura do milho cenário regular (Figura 7) as áreas da classe Alta abrangem $903,34 \mathrm{~km}^{2}$, representando $1,6 \%$ da área total (Tabela 5), com ocorrência das subclasses A3 e A4, predominando a subclasse A3. Estas classes ocorrem na região do Litoral e no Sertão, notadamente em ambientes por apresentarem solos de potencial pedológico Alto, e aptidão climática plena com período chuvoso prolongado. Já os ambientes de potencial Médio abrangem 4.284,99 $\mathrm{km}^{2}$, representando 7,6\% da área, com ocorrência das subclasses M1, M2, M5, M6, M7 e M8, com predomínio da subclasse M1. Estas classes ocorrem principalmente na região do Litoral, Agreste e Sertão, notadamente em ambientes por apresentarem solos de potencial pedológico Médio, e aptidão climática Plena e Moderada por deficiência. 


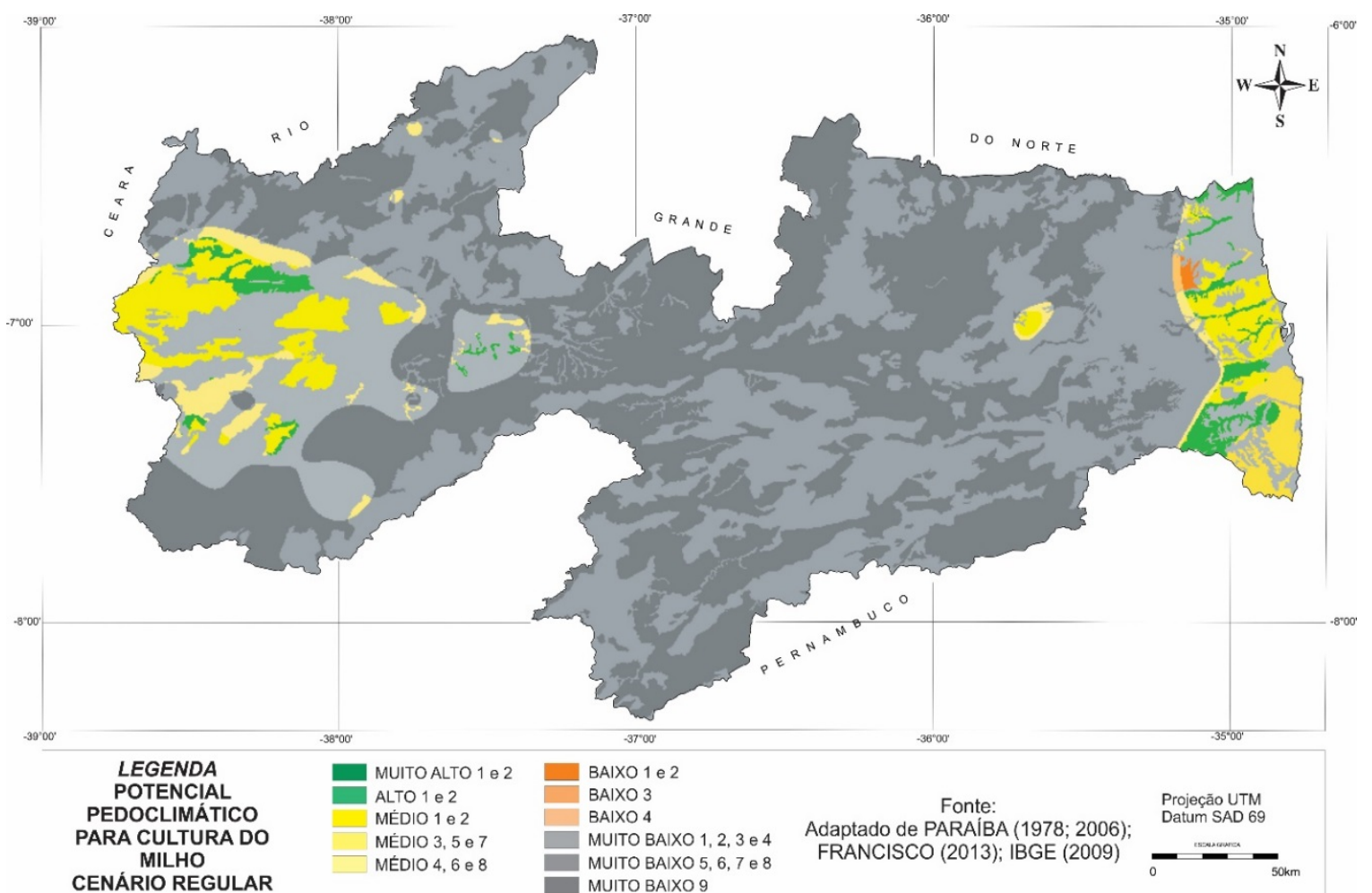

Figura 7. Potencial pedoclimático para cultura do milho cenário regular.

As áreas de potencial Baixo contemplam os ambientes com fortes limitações de solo e/ou de clima, abrangem $89,27 \mathrm{~km}^{2}$, representando 0,16\% da área total (Tabela 5), com ocorrência das subclasses B1 e B4 predominando a subclasse B1. Esta classe ocorre em pequenas áreas no Litoral e Agreste por apresentar aptidão climática Moderada por deficiência hídrica e estar localizado em solos com potencial pedológico Baixo para a cultura. As áreas de potencial Muito Baixo contemplam os ambientes com fortes limitações de solo e/ou de clima, abrangem 51.094,41 $\mathrm{km}^{2}$, representando $90,64 \%$ da área total, com ocorrência das subclasses MB1, MB2, MB4, MB6, MB7 e MB9, predominando a subclasse MB9. Estas classes ocorrem em quase todo o Estado por apresentarem aptidão climática Inapta.

No mapa de potencial pedoclimático para cultura do milho cenário chuvoso (Figura 8) observa-se que as áreas da classe Alta abrangem $3.354,1 \mathrm{~km}^{2}$, representando 5,95\% da área total (Tabela 5), com ocorrência das subclasses A3 e A4, predominando a subclasse A4. Estas classes ocorrem em pequenas áreas na região do Agreste, Brejo e no Sertão, notadamente em ambientes por apresentarem solos de potencial pedológico Alto, e aptidão climática plena com período chuvoso prolongado. Este resultado deve-se a baixa fertilidade dos solos. Silva et al. (2012) elaborando o zoneamento para o Estado de Alagoas observou para esse potencial $14 \%$ da área total localizadas nos Tabuleiros região do Litoral. Os ambientes de potencial Médio abrangem $9.675,44 \mathrm{~km}^{2}$, representando 17,16\% da área, com ocorrência das subclasses M1, M2, M5, M6, M7 e M8, com predomínio da subclasse M2. Estas classes se distribuem na região do Litoral, Agreste, Brejo e Sertão. Notadamente em ambientes por apresentarem solos de potencial pedológico Médio, e aptidão climática Plena e Moderada por deficiência. EMBRAPA (2013) observou para o Estado de Alagoas um percentual de $36 \%$ da área, representação muito maior em relação a área do Estado da Paraíba. 


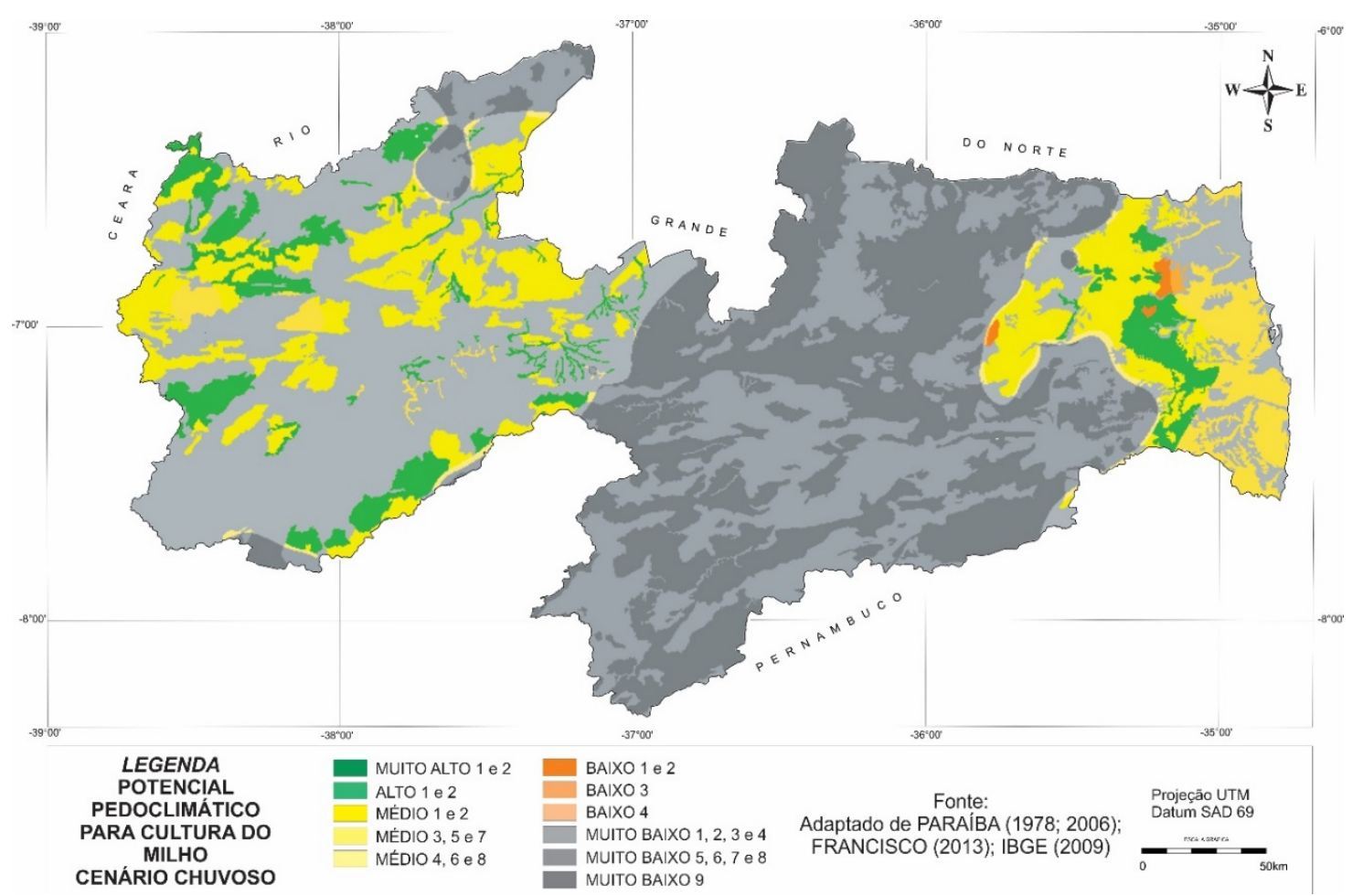

Figura 8. Potencial pedoclimático para cultura do milho cenário chuvoso.

Já as áreas de potencial Baixo contemplam os ambientes com fortes limitações de solo e/ou de clima, abrangem 166,46 $\mathrm{km}^{2}$, representando 0,3\% da área total, com ocorrência das subclasses B1, B2, B3 e B4 predominando a subclasse B2. Esta classe ocorre em pequenas áreas no Litoral por apresentar aptidão climática Moderada por deficiência hídrica e estar localizado em solos com potencial pedológico Baixo para a cultura. Por fim, as áreas de potencial Muito Baixo contemplam os ambientes enquadrados nesse potencial com fortes limitações de solo e/ou de clima, abrangem 43.175,99 $\mathrm{km}^{2}$, representando 76,59\% da área total, com ocorrência das subclasses MB1, MB2, MB3, MB4, MB6, MB7, MB8 e MB9, predominando a subclasse MB9. Estas classes ocorrem sob o Planalto da Borborema, no Agreste, e pequena área no Sertão por apresentarem aptidão climática Inapta. Esses fatores restritivos geralmente estão associados à limitação pedológica pela presença de pedregosidade, profundidade efetiva, textura arenosa e relevo com declividades maiores principalmente em ambientes que apresentação restrições ao uso da mecanização agrícola. EMBRAPA (2013) observou resultados similares encontrados neste trabalho, devido às áreas estarem localizada na região semiárida.

PARAIBA (1978) observou que a exploração da cultura do milho tem uma grande difusão e encontra-se distribuída em todo o interior do Estado principalmente em áreas de subsistência e cultivadas em consórcio.

\section{CONCLUSÕES}

São observadas diferenças significativas na extensão territorial das classes e subclasses de potencial, que apresenta variações de ordem pedológica e climática em seu território, influenciando no potencial pedoclimático para a cultura do milho.

As áreas de potencial Muito Alto não foram mapeadas por esta metodologia.

Os ambientes de potencial Baixo e Muito Baixo ocorrem em maior magnitude na região semiárida e tendem aumentar sua abrangência à medida que se acentua o grau de deficiência hídrica principalmente no cenário seco.

\section{AGRADECIMENTOS}


Ao CNPq/Fapesq pela concessão de bolsa de pesquisa ao primeiro autor.

\section{REFERÊNCIAS}

ASSIS, F. N.; ARRUDA, H. V. DE; PEREIRA, A. R. Aplicações de estatística à climatologia: teoria e prática. Pelotas: UFPel, 1996. 161p.

CAVALCANTI, E. P.; SILVA, E. D. V. Estimativa da temperatura do ar em função das coordenadas locais. In: CONGRESSO BRASILEIRO DE METEOROLOGIA, 8, 1994. Belo Horizonte, Anais...Belo Horizonte: SBMET, 1, p.154-157, 1994.

CAVALCANTI, E. P.; SILVA, V. DE P. R.; SOUSA, F. DE A. S. Programa computacional para a estimativa da temperatura do ar para a região Nordeste do Brasil. Revista Brasileira de Engenharia Agrícola e Ambiental, v.10, p.140-147, 2006.

CONAB. Companhia Nacional de Abastecimento. Avaliação da Safra Agrícola 2006/2007 - Sétimo Levantamento. Ministério da Agricultura, Pecuária e Abastecimento, Abril, 2007. Acesso em: 6/03/2016. Disponível em:

http://www.bibliotekevirtual.org/simposios/8S

BCMAC/8sbcmac-a046.pdf.

EMBRAPA. Zoneamento Agroecológico do Estado de Alagoas - ZAAL. ViZon. Embrapa Solos, UEP Recife, 2013. CDROM.

EMBRAPA. Embrapa Milho e Sorgo. Sistema de Produção, 1. Cultivo do Milho. Clima e Solo. 2000. Disponível em: http://www.cnpms.embrapa.br/publicacoes/mil ho_1_ed/clima.htm. Acesso em: 30 de julho de 2016.

EMBRAPA. Zoneamento Agroecológico do Estado de Alagoas. Potencial Pedológico do Estado de Alagoas para Culturas Agrícolas. Relatório Técnico. Convênios SEAGRIAL/Embrapa Solos Nos 10200.04/0126-6 e 10200.09/0134-5. Recife: Embrapa Solos, 2012. $123 p$.

$$
\text { Disponível }
$$

em: http://ainfo.cnptia.embrapa.br/digital/bitstream/ item/77202/1/Relatorio-Pot-Pedologico.pdf.

Acesso em: 15 de novembro de 2014.

FRANCISCO, P. R. M. Classificação e mapeamento das terras para mecanização do Estado da Paraíba utilizando sistemas de informações geográficas. 122f. Dissertação (Mestrado em Manejo de Solo e Água). Centro de Ciências Agrárias. Universidade Federal da Paraíba. Areia, 2010.

FRANCISCO, P. R. M.; CHAVES, I. DE B.; LIMA, E. R. V. DE. Classificação de terras para mecanização agrícola e sua aplicação para o Estado da Paraíba. Revista Educação Agrícola Superior, v.28, n.1, p.30-35, 2013.

FRANCISCO, P. R. M.; CHAVES, I. de B.; LIMA, E. R. V. de; SANTOS, D. Tecnologia da geoinformação aplicada no mapeamento das terras à mecanização agrícola. Revista Educação Agrícola Superior, v.29, n.1, p.4551, 2014.

FRANCISCO; P. R. M.; MEDEIROS; R. M. DE; MATOS, R. M. DE; MARIA MARLE BANDEIRA, M. M.; SANTOS; D. Análise e Mapeamento dos Índices de Umidade, Hídrico e Aridez através do BHC para o Estado da Paraíba. Revista Brasileira de Geografia Física, v.8 n. 4, p.1093-1108, 2015.

IBGE. Instituto Brasileiro de Geografia e Estatística. 2009. Disponível em: http://www.ibge.gov.br. Acesso em: 12 de março de 2011.

LEPSCH, I. F.; BELLINAZZI JR., R.; BERTOLINI, D.; ESPÍNDOLA, C. R. Manual para levantamento utilitário do meio físico e classificação de terras no sistema de capacidade de uso. 4a Aprox. SBCS, Campinas-SP, 1996, 175p.

LOGUERCIO, L. L.; CARNEIRO, N. P.; CARNEIRO, A. A. Milho Bt: Alternativa biotecnológica para controle biológico de insetos-praga. Biotecnologia Ciência \& Desenvolvimento, n.24, p.46-52, 2002. 
MASSEY JR, F. J. The Kolmogorov-Smirnov test of goodness of fit. Journal of American Statistical Association, v.46, p.68-78, 1980.

MIELKE, P. W. Simple iterative procedures for two-parameter gamma distribution maximum likeliwood estimates. Journal of Applied Meteorology, v.15, n.12, p.181-183. 1976.

PARAÍBA. Governo do Estado. Secretaria de Agricultura e Abastecimento - CEPA-PB. Zoneamento Agropecuário do Estado da Paraíba. Relatório ZAP-B-D-2146/1. UFPBEletro Consult Ltda., 1978. 448p.

PARAÍBA. Secretaria de Estado da Ciência e Tecnologia e do Meio Ambiente. Agência Executiva de Gestão de Águas do Estado da Paraíba, AESA. PERH-PB: Plano Estadual de Recursos Hídricos: Resumo Executivo e Atlas. Brasília, DF, 2006. 112p.

SILVA; A. B. DA; AMARAL, A. J. DO; BARROS; A. H. C.; ACCIOLY, L. J. DE O.; SANTOS, J. C. P. DOS; ARAÚJO FILHO, J. C. DE; OLIVEIRA NETO, M. B. DE; PARAYBA, R. DA B. V.; GOMES, E. C. Potencial Pedoclimático do Estado de Alagoas Para a Cultura do Milho em Manejo com Alta Tecnologia, Manejo C e Cenário Chuvoso Regular. In: CONGRESSO NACIONAL DE MILHO E SORGO, 29, Águas de Lindóia, 2012. Anais... Águas de Lindóia, 2012.

SILVA, R. M. DA; SILVA, L. P. E; MONTENEGRO, S. M. G. L.; SANTOS, C. A. G. Análise da variabilidade espaço-temporal e identificação do padrão da precipitação na Bacia do Rio Tapacurá, Pernambuco. Sociedade \& Natureza, n.22, v.2, p.357-372. 2010.

SOUZA, L. D; SOUZA, L. S. Clima e solo. In: MATTOS, P. L. P.; GOMES, J. C. O cultivo da mandioca. Embrapa Mandioca e Fruticultura Tropical. Circular Técnica, 37. Cruz das Almas: Embrapa Mandioca e Fruticultura Tropical, 2000. p.11-13.

THOM, H. C. S. A note on the gama distribution. Monthly Weather Review, v. 86, p. 117-122. 1958.

THORNTHWAITE, C. W. An approach toward a rational classification of climate. Geographic Review, v.38, p.55-94, 1948.

THORNTHWAITE, C. W.; MATHER, J. R. The water balance. Publications in Climatology. New Jersey: Drexel Institute of Technology, 1955. 104p.

VAREJÃO-SILVA M. A.; BRAGA, C. C.; AGUIAR M. J. N.; NIETZCHE M. H.; SILVA, B. B. Atlas Climatológico do Estado da Paraíba. UFPB, Campina Grande, 1984.

VAREJÃO-SILVA, M. A. Meteorologia e climatologia. Brasília, DF: INMET, 515p. 2001.

VAREJÃO-SILVA, M. A; BARROS, A. H. C. Zoneamento de aptidão climática do Estado de Pernambuco para três distintos cenários pluviométricos. Secretaria de Produção Rural e Reforma Agrária de Pernambuco, Recife, 2002. 51p. 